\title{
The Cultural Aspect of Differences in Company Performance across Countries: Gray's Accounting Values Contribute more than Hofstede' S Original Cultural Dimensions
}

Finn Schoeler*

Department of Economics and Business, Economics School of Business and Social Sciences, Aarhus University, Denmark

\begin{abstract}
Comparability through uniform accounting standards is one of IASB's goals, but several country-wise differences make this hard, even across companies in countries prescribing the same accounting regime, like IFRS. Among other issues, the performance measures, ROA, Tobin's Q, Earnings-to-Enterprise Value and Sales-to-Enterprise, are affected by culture as expressed by both Hofstede and Gray.

We selected financial data from 22,445 companies in 95 countries from the global ORBIS-database, and available information from PWC on the country-wise use and implementation of IFRS.

We found a clear cultural effect explaining the differences in company performance across countries and accounting regimes, and that the Gray accounting values are apparently marginally preferable than the Hofstede cultural indicators.
\end{abstract}

Keywords: Financial accounting information; IFRS; Hofstede cultural indicators; Gray accounting values; Comparability

JEL Classification: G15, G38, M40, M41, M48

\section{Introduction}

Comparability of the financial information presented by companies is one of the objectives of countries' switching from using local accounting practices to the IFRS Framework. One reason for difficulties when comparing performance in companies could be different mandated accounting regimes where different accounting methods are prescribed for a specific accounting. This is what Ding et al. [1] calls divergence. Likewise, some accounting issues might not be covered in one or both accounting regimes, which is what Ding et al. [1] calls absence. But even across countries prescribing the same accounting regime, difficulties can be observed, as is the case for listed companies in the European Union. Accounting practice evolve differently across countries and industries because business relations evolve differently, and business relations differ because of different environmental "influences", like political and legal systems, economics and culture $[2,3]$.

Hofstede [4,5] documents that people are organized, do things, and think differently in different countries as suggested in his wellknown cultural indicators. Based on this framework on cultural differences, Gray [6] and later Radebaugh et al. [7] map the indicators into accounting values by transforming the cultural differences into accounting constructs based on how the cultural indicators are hypothesized to affect accounting practice and systems.

DeFranco et al. [8] points out that the same economic income and value must reflect the same return statistics, and if corrected for industry characteristics and competition effects across countries, comparability is the quality of information that enables users to identify similarities and differences between the outcomes from companies' accounting systems. When we correct the economic performance on a company level with observable industry and country differences, the adjusted economic company performance can be expected to be homogenous across countries, i.e. a distribution around the average where the variation reflects differences in management and composition of employees. If financial statements come from companies using different accounting regimes it is likely that accounting regime related divergence and absence alone affect the presented financial measures such that they are not comparable. However, is it really likely that prescription of one set of accounting standards to avoid divergence and absence is enough to ensure comparability? Where the focus for DeFranco et al. [8] is on the idea that the accounting system is mapping from economic events to financial statements, Gray focus on the cultural effect in the mapping. In accordance with both the HofstedeGray setting and the Nobes, respectively the Zarzeski points-of-view, this would lead to at least better comparability if also their disturbing points were corrected.

The rest of the paper is structured in the following way: In section 2 we the motivation and literature review for the study is presented by examining literature on the cultural aspects of the creation of financial statement information, and we develop our hypotheses. In section 3 we describe the research design as well as the data collection procedure. In section 4 we present our results and discuss some implications. In the end we conclude the paper in section 5 .

\section{Motivation, Literature Review and Hypotheses}

In the IASB Framework [9] it is stated in paragraph 2.25 that "Comparability is the goal: consistency helps to achieve that goal". The enhancing qualitative characteristics, like comparability, enable users to identify differences and similarities among items within financial

*Corresponding author: Finn Schoeler, Department of Economics and Business Economics School of Business and Social Sciences, Aarhus University, Denmark Tel: 8716 5397; E-mail: fsc@econ.au.dk

Received June 06, 2018; Accepted July 05, 2018; Published July 16, 2018

Citation: Schoeler F (2018) The Cultural Aspect of Differences in Company Performance across Countries: Gray's Accounting Values Contribute more than Hofstede's Original Cultural Dimensions. J Account Mark 7: 287. doi: 10.4172/21689601.1000287

Copyright: (c) 2018 Schoeler F. This is an open-access article distributed under the terms of the Creative Commons Attribution License, which permits unrestricted use, distribution, and reproduction in any medium, provided the original author and source are credited. 
statements. DeFranco et al. [7] add structure to this idea by formalizing the accounting system as a function that maps from economic events to financial statements enabling users to identify differences and similarities between two sets of economic phenomena. Following this logic, two companies with comparable accounting systems should have similar mapping functions, and thus present similar financial statements for a given set of economic events.

The IASB Framework [9] states in paragraph 2.27 that "Comparability is not uniformity", and continues "for information to be comparable, like things must look alike and different things must look different". According to Sunder [10], since no two transactions or events are identical in all respects, the real question is whether uniformity means that any two transactions with any similarity must be treated alike, or if uniformity means that any two transactions with any dis- similarity must be treated differently. However, those advocating for the conceptual framework argue that a uniform set of standards increases comparability when it is faithfully applied (i.e. credibly implemented and resulting in an increase in uniformity), and that a universal financial language offers many advantages: Cross-border businesses must benefit from reduced preparation costs and from a reduction in the cost of raising capital. Further, it can be expected that cross- border trading in securities increases as international investors can more easily compare the performance of companies based in different countries.

However, the accounting system is not only affected by the prescribed accounting standards, but also their practical use. According to Nobes [3] culture is one of the main factors causing accounting differences across countries as well as across companies. According to Nobes [3] the legal system and the capital market are two distinct and quite country-specific institutional elements which are influenced by culture and as such highly affect how the accounting regime is developed in a country. Other factors affecting companies' operations in different countries, which as such could be called the country business climate, are also likely to influence the economic performance as well as how the specific transactions are transformed into financial statements. Thus, if following the DeFranco et al. [8] premise, the conceptual mapping of companies' economic performance into financial statement performance could be expected to be very informative country-wise, presenting an average level and corresponding variation.

Violet [11] was one of the first to suggest that accounting is not culture-free. He argued that accounting should be seen as a 'sociotechnological activity' involving interaction between both human and non-human resources, and consequently culture is often a very important factor when comparing available financial accounting information. Thus, different accounting regimes, practices, approaches, and audit behavior related to the production of this information should be considered as reflecting culture, even though this is not the only factor.

Hofstede [4,5] considers culture as 'the collective programming of the mind which distinguishes the members of one human group from another'. Originally, Hofstede used responses to an attitude survey of IBM employees worldwide to identify cultural dimensions across countries: Power distance (PDI), Individualism (IDV), Masculinity (MAS), Uncertainty avoidance (UAI) and later also Long-term orientation (LTO). Power distance refers to the extent to which hierarchy and unequal power distribution in organizations are accepted. Individualism refers to a preference for a loose social structure rather than a tight social structure (collectivism). Masculinity refers to a focus on traditional masculine values of performance and achievement rather than feminine values of relationships, nurturing and caring. Uncertainty avoidance refers to the degree to which individuals feel uncomfortable with ambiguity and uncertainty. Longterm orientation refers to the preference of encouraging people's focus on future rewards, thrift and endurance.

Based on a thorough review of accounting literature and practice Gray [6] identified four widely recognized accounting values, Professionalism, Uniformity, Conservatism, and Secrecy, and established a linkage between them and Hofstede's four cultural dimensions. Later, when Hofstede [5] had added his fifth cultural dimension, Radebaugh et al. [7] extended Gray's original description of these four accounting values making references to Hofstede's five cultural dimensions as follows:

- Professionalism (PROF) shows a preference for individual professional judgment and maintenance of professional self-regulation as opposed to compliance with prescriptive legal requirements and statutory control. The higher a country scores in terms of Individualism and Masculinity, and the lower it scores in terms of Uncertainty Avoidance and Power Distance, the more likely it is to be categorized highly in terms of Professionalism.

- Uniformity (UNIF) shows a preference for uniform accounting practices between companies and for consistent use of such practices over time as opposed to flexibility in accordance with the perceived circumstances of individual companies. The higher a country scores in terms of Uncertainty Avoidance and Power Distance and the lower it scores in terms of Individualism, the more likely it is to be categorized highly in terms of Uniformity.

- Conservatism (CONS) shows a preference for a cautious approach to measurement to cope with the uncertainty of future events as opposed to a more optimistic and risk-taking approach. The higher a country scores in terms of Uncertainty Avoidance and Long-Term Orientation and the lower it scores in terms of Individualism and Masculinity, the more likely it is to be categorized highly in terms of Conservatism.

- Secrecy (SECR) shows a preference for confidentiality and restrictions on disclosure of information about the business only to those who are closely involved with its management and financing as opposed to a more transparent, open, and publicly accountable approach. The higher a country scores in terms of Uncertainty Avoidance, Long Term Orientation and Power Distance and the lower it scores in terms of Individualism and Masculinity, the more likely it is to be categorized highly in terms of Secrecy.

The four relationships are presented in brief below in Table 1. It is important to emphasize that the concepts are only verbal descriptions where focus is on links and relative influence on each other, while the absolute relations are not considered (Table 1).

Gray [6] and Radebaugh et al. [7] use the expressions strong, less strong, and weak to describe the relationships between the cultural dimensions and the accounting values as shown in Table 1. To facilitate a weighted combination of the multiple elements comprising an accounting value, we translate this into a weight of four, two, and one for strong, less strong, and weak, respectively for our adjustment for cultural influence. Hereby, a relationship described as strong carries twice the effect of a relationship described as less strong, and similarly a relationship described as less strong carries twice the effect in our weighting method as a relationship described as weak when the accounting values are calculated. 
Citation: Schoeler F (2018) The Cultural Aspect of Differences in Company Performance across Countries: Gray's Accounting Values Contribute more than Hofstede's Original Cultural Dimensions. J Account Mark 7: 287. doi: 10.4172/2168-9601.1000287

Page 3 of 8

\begin{tabular}{|c|c|c|c|c|}
\hline \multirow[b]{2}{*}{ Cultural indicators (from Hofstede) } & \multicolumn{4}{|c|}{ Accounting values (from Gray) } \\
\hline & $\begin{array}{l}\text { Professionalism } \\
\text { (PROF) }\end{array}$ & $\begin{array}{l}\text { Uniformity } \\
\text { (UNIF) }\end{array}$ & $\begin{array}{l}\text { Conservatism } \\
\text { (CONS) }\end{array}$ & $\begin{array}{l}\text { Secrecy } \\
\text { (SECR) }\end{array}$ \\
\hline Power Distance (PDI) & + & +++ & ++ & +++ \\
\hline Individualism (IDV) & +++ & + & + & + \\
\hline Masculinity (MAS) & +++ & ++ & + & + \\
\hline Uncertainty Avoidance (UAI) & + & +++ & +++ & +++ \\
\hline Long-Term Orientation (LTO) & + & ++ & +++ & +++ \\
\hline
\end{tabular}

Note: '+++' indicate a strong relationship; '++' indicate a less strong relationship; and '+'indicate a weak relationship.

Table 1: The connection between Hofstede and Gray.

Since Gray first made his accounting values, there have been several contributions in the literature attempting to extend, test and refine the relations in Table 1, i.e. understanding the influence of culture on accounting. Perera [12] provides additional discussion of the Grayhypotheses in respect of the claimed relationships and considered both Hofstede's cultural indicators and Gray's accounting value dimensions and uses them to explain apparent differences in accounting practices adopted in continental European countries versus in Anglo-American countries.

Noravesh et al. [13] examine the relationships between cultural indicators defined by Hofstede and accounting values described by Gray in Iran by use of Structural Equation Models. The authors confirm eight out of thirteen of Gray's original hypotheses. Contrary to Gray they find no positive relationship between: a) uncertainty avoidance and secrecy hypothesis, b) uncertainty avoidance and uniformity hypothesis, c) individualism and professionalism hypothesis. Further, they found positive linkage between: a) power distance and conservatism hypothesis, and b) masculinity and professionalism hypothesis.

Salter and Lewis [14] tested relationships between one of Gray's accounting values - conservatism and Hofstede's cultural dimensions using actual reported data $(1998$ - 2004) from SEC form 20-F. They found that the cultural variable of individualism is significantly and positively related to differences in income measurement practices between countries, and that a country's membership in the European Union and corporate tax rate are related to differences in income measurements practices.

Tsakumis [15] explicitly tests two of the Gray framework's accounting value, conservatism and secrecy, at the individual level, since he compares Greece and the US, by asking 101 participants with on average more than fifteen years of professional accounting experience for their opinion on recognition and disclosure of contingent assets and contingent liabilities. With respect to the accounting value of secrecy, the experiment showed that Greek accountants were less likely than their US counterparts to disclose the existence of both contingent assets and contingent liabilities.

The secrecy and conservatism accounting values were also the focus for Doupnik and Riccio [16] when they studied whether differences in culture cause accountants in distinct countries to interpret and apply the same financial reporting standards differently. The study focused on the use of two accounting standards that require accountants to exercise their judgment, namely the standards relating to income increasing and decreasing, IAS 18 on Revenues and IAS 11 on Construction contracts. The authors found a strong relationship between the conservatism hypothesis and recognition of income increasing items but no relationship between this hypothesis and recognition of income-decreasing items. However, strong relationships were obtained between the secrecy hypothesis and disclosures of financial information.

Jaggi and Low [17] investigate the role of culture and legal origin in explaining disclosure levels. The dependent variable is a disclosure index, for which the validity can be discussed. The conclusions are that national cultural values do not appear to have considerable influence on financial disclosures. Braun and Rodriguez [18] found positive relationship between earnings management and Gray's [6] data in a quantified accounting values numbers study in 31 countries and by using earnings management measures developed in Leuz et al. [19].

Chanchani and Willet [20] present an accounting values survey meant to measure a country's accounting values via financial statement preparers' and users' concrete actions in India and New Zealand. When choosing these two English using countries, they avoid translation issues in the survey and they received responses from 1,104 respectively 510 from India respectively New Zealand. The results provide some support for the usefulness of Gray's [6] accounting values but questions were raised as to adaption and reinterpretation of accounting values as well as possible existence of other not yet recognized accounting value constructs.

The Hofstede-Gray setting has also been subject to criticism. Already Chanchani and MacGregor [21] examined and questioned the literature focusing on the conceptual and theoretical issues of the Hofstede-Gray model, while Doupnik and Tsakumis [22] investigated the literature concerning the empirical testing of the theory relating culture to global diversity in financial reporting. McSweeney [23] claimed that the Hofstede model as the starting-point suffered from five issues related to crucial methodological assumptions, all questionable. For instance: The people surveyed were similar in every respect other than their nationality, since they were all sales, project or marketing people employed by IBM for which reason they cannot in any way be claimed to be representative for the specific country's culture as such, and consequently the causality relating the results to country differences as such can be questioned. And because of this severe violation of one of the key assumptions, McSweeney [23] claimed that the whole study can be questioned. Baskerville [24] questions the use of national country-wise cultural indices misleading to a dependence on cultural indices as an explanatory variable of differences in accounting practices and behavior, due to alleged problems in the assumption of equating nation with culture; the difficulties of and limitations on a quantification of culture represented by cultural dimensions and matrices; and the status of the observer outside the culture. Schwartz [25] finds that Hofstede [4,5] lack theoretical foundation, and Shenkar [26] finds Hofstede [4,5] outdated. Others (Hope [27]; Jaggi and Low [16]; Zarzeski [2]) have constructed and used country specific disclosure indexes to focus specifically on the secrecy accounting value, finding full to partial support for Gray's [6] accounting values in many ways, but in general a drawback to many studies is the subjectivity inherent 
in the method of quantification of accounting values (Chanchani and MacGregor [21]; Doupnik and Tsakumis [22]. Doupnik and Tsakumis [22] attempted to determine whether the Gray [6] framework had been subjected to adequate empirical inquiry to prove its validity and summarized the research methodologies employed to test the theory. However, the mixed results of all these studies indicate that the validity of cultural dimension theories needs further testing, and as Joannides et al. [28] suggest, also the critiques on the Hofstede-Gray setting can be questioned.

For our study we trust the general economic assumption that it will not be possible to maintain a higher (lower) average level and variation of performance in a selected country in the very long run. However, if this should happen in a shorter run, our estimated country performance level reflects the "observed" difference from the expected overall business performance in countries as presented in the officially published notions on country "performance" in The Global Competitiveness Report 2015-2016 from World Economic Forum (WEF - see Schwab, 2016). Further, we find observable differences in coherent business performance in different industries and add adjusted company-based accounting information to the analyses.

For our analyses we use four classic company performance-related financial accounting-based ratios: Tobin's Q, the Earnings vs. Enterprise Value, the Sales vs. Enterprise Value; and the Return on Assets. These four financial ratios are fair and commonly used measures of company business performance. Concerning the actual sizes of these measures, the observable accounting figures must be a function of Industry; Economic climate (at country-level); Culture; Accounting regime; Management; and Noise. To make the comparison of the country level performance fair, we use two sets of performance measures: (a) we treat the companies in each country on equal basis, and

(b) We treat the companies in each country weighted in accordance with each company's market value of equity. Additionally, we use two tracks for our analyses; one using the observed performance measures as they are; and one using the industry-adjusted measures. The two tracks should not be competing since we a priori expect the relationships to be clearer when the industry- adjusted measures are used, since we here deliberately eliminate one crucial factor from the analyses. Consequently, any remaining differences must be caused by Management's influence, Accounting regime and Noise.

In each track the starting point is 95 calculated country-based performance measures, equal and weighted respectively, and Industry adjusted and Industry non-adjusted respectively. The assumption is that the levels in different countries for the performance measures reflect the economic climate in the different countries as proxied by the WEF-index. Since introducing accounting regimes as explanatory variable should be the same as eliminating one of the factors that might disturb the relations, this would be expected to give a better model. Hereafter we introduce culture by using the five Hofstede country-based cultural indicators, together within accounting regimes and separately, since we hereby eliminate the cultural factor - both with accounting regime and without. And lastly, we introduce Gray's four countrybased accounting values instead of Hofstede's cultural indicators, since we rely on Gray's hypothesized relations. The comparison of results from company complete model using Hofstede and Gray respectively is an indirect test of the Gray hypothesized framework. More formally stated, we hypothesize that (Table 1).

- H1: The country-based level of observable financial performance ratios will be different but show same pattern as observable WEF-country performance; and introduction of four different accounting regimes, i.e. IFRS as published by IASB, IFRS as adopted by EU, IFRS allowed (as adopted locally or incomplete), and IFRS disallowed, will make the relation stronger.

- H2: The country-based level of observable financial performance ratios will be different but show same pattern as observable WEF-country performance; and introduction of four different accounting regimes, i.e. IFRS as published by IASB, IFRS as adopted by EU, IFRS allowed (as adopted locally or incomplete), and IFRS disallowed, and introduction of Hofstede's five culture indicators, PDI, IDV, MAS, UAI, and LTO will make the relation remarkably stronger.

- H3: The country-based level of observable financial performance ratios will be different but show same pattern as observable WEF-country performance; and introduction of four different accounting regimes, i.e. IFRS as published by IASB, IFRS as adopted by EU, IFRS allowed (as adopted locally or incomplete), and IFRS disallowed, and introduction of Gray's four accounting values, PROF, UNIF, CONS, and SECR will make the relation even stronger than the use of Hofstede's five cultural indicators.

\section{Data Selection and Research Design}

Having access to the ORBIS-database we selected all listed nonfinancial and non-insurance companies during May 2016, which left us with more than 40 thousand public accounts from more than 100 different countries from all over the world, and from 46 different industries using the Fama-French classification Fama and French [29].

Based on available information from PriceWaterhouseCoopers' most recent publication [30] on IFRS adoption by country, we categorized each country's accounting regime: is IFRS required or permitted or not allowed for listed companies in the country. We also considered which "version" of IFRS is referred to, all of which made us classify the countries' accounting regimes as: (i) Mandatory IFRS (as prescribed by the IASB); (ii) Mandatory EU (as published by IASB and accepted by the EU); (iii) Allowed (as adapted locally or simply permitted); (iv) Disallowed (since another GAAP is prescribed).

Since the Hofstede cultural indicators (PDI, IDV, MAS, UAI, and LTO) unfortunately are not available for all countries in the World, we deselected the companies from those quite few countries where no calculated Hofstede indicators were found (via his website on 18 April 2016).

Additionally, we demanded available data from at least 5 companies in each country to have an acceptable basis for country level statistics. The minimum target of 5 companies in each country was set since a preferred larger number (say 30) would have halved the number of participating countries in the study. In Table 2 we present country based descriptive statistics for economic climate (WEF), Hofstede cultural indicators, and Gray accounting values (Table 2).

Companies which did not have complete datasets as well as companies with negative equity were deleted, and the remaining result was 22,445 valid companies from 95 different countries. During our analyses of performance measures, we make three structured adjustments to the performance measures in the complete dataset, and as it is quite common in many empirical studies using financial ratios, we deal with extreme cases by winsorizing ( 1 per cent) the dataset, i.e. each outlier is replaced with the next highest score which is not an outlier. 
Citation: Schoeler F (2018) The Cultural Aspect of Differences in Company Performance across Countries: Gray's Accounting Values Contribute more than Hofstede's Original Cultural Dimensions. J Account Mark 7: 287. doi: 10.4172/2168-9601.1000287

Page 5 of 8

According to classic studies, like DeFranco et al. [7], an appropriate way to analyze the relationship and hereby also our hypotheses is to test the more concrete contribution from the data and using OLS-regression in several different combinations of the central variables. The different performance measures, equal and weighted country measures as well as industry adjusted and industry non-adjusted, are modeled together with the different culture variables, and finally all the different models are compared. We use the following relation as our overall "complete" model for guidance and evaluation of the various parts' contribution.

\section{Performancei $=\beta 0+\beta 1 \mathrm{WEFi}+\beta 2 \mathrm{ARi}+\beta 3 \mathrm{HOFi}+\beta 4 \mathrm{GRAYi}+\zeta \mathrm{i}$}

Since our focus is the marginal contribution to the total setting by the various parts we use a stepwise testing procedure. In the first step, we model the basic non-nested variables as independent, i.e. the WEF country business climate. In the second step, we introduce the four different accounting regimes as independent variables, i.e. the WEF country business climate, and three accounting regime dummy variables. In the third step we add the five Hofstede culture indicators to the model, and focus on the extra contribution that these variables introduce. In the fourth step we replace the five Hofstede culture indicator variables with the four Gray accounting values in the model. This last change forms the basis for evaluating Gray versus Hofstede.

Based on classic literature on econometrics and multiple regression analyses we evaluate the different models using the adjusted $\mathrm{R} 2$ and Akaike model selection criteria as means to evaluate and compare the different models. Additional considerations like management influence, institutional differences, etc. could also have been included, but such issues are disregarded here.

\section{Findings and Implications}

In Table 3 we present key descriptive statistics for our chosen four performance measures to give an indication of the variation in the sample for industry adjusted and industry non-adjusted statistics as well as for equal weighted and market value of equity weighted statistics for the 95 countries. Additionally, we show the performance for Return on Assets divided into the four accounting regimes - likewise differences could be shown for the other three performance measures. As it seems quite clear, our Return on Assets; Earnings-Enterprise Value multiple; Sales-Enterprise Value multiple; and Tobin's Q, show some clear differences across the four different accounting regimes as well as for the total sample (Table 3).

The differences between industry adjusted and industry nonadjusted ratios are not obvious since pairwise comparisons of the performance levels only show smaller differences for all the presented combinations. However, when company equal and weighted performance measures are compared

Pairwise, the weighted seems larger for ROA, Tobin's $Q$ and Earnings-Enterprise value indicating that the larger companies' country wise seem more profitable, while the Sales-Enterprise value shows the opposite, and consequently the larger companies do not present the largest sales numbers.

Concerning our set of hypotheses, we chose to present detailed results for the equal weighted ROA measure since ROA presumably is one of the most often used performance measures based on the annual financial reports. The use of the other performance measures leads to same patterns for the results as shown here. The use of ROA-variables for explaining the link between performance levels and country based

\begin{tabular}{|c|c|c|c|c|c|c|}
\hline & & Mean & Std. error & Minimum & Maximum & Median \\
\hline \multicolumn{2}{|c|}{ WEF country performance (WEF) } & 4.5325 & 0.6096 & 3.4500 & 5.7600 & 4.3900 \\
\hline Hofstede & Power distance (PDI) & 0.6154 & 0.0211 & 0.1100 & 1.0400 & 0.6400 \\
\hline cultural & Individualism (IDV) & 0.3969 & 0.0227 & 0.0800 & 0.9100 & 0.3300 \\
\hline $\begin{array}{c}\text { Indicators } \\
\text { (HOF) }\end{array}$ & Masculinity (MAS) & 0.4816 & 0.0182 & 0.0500 & 1.0000 & 0.5000 \\
\hline & Uncertainty avoidance (UAI) & 0.6513 & 0.0218 & 0.0800 & 0.0700 & 0.6500 \\
\hline & Long-term orientation (LTO) & 0.4200 & 0.0253 & 0.1200 & 1.1800 & 0.3800 \\
\hline \multirow{2}{*}{$\begin{array}{c}\text { Gray } \\
\text { accounting }\end{array}$} & Professionalism (PROF) & 0.4708 & 0.0111 & 0.3278 & 0.7578 & 0.4622 \\
\hline & Uniformity (UNIF) & 0.5590 & 0.0112 & 0.2615 & 0.7885 & 0.5615 \\
\hline \multirow{2}{*}{$\begin{array}{l}\text { values } \\
\text { (GRAY) }\end{array}$} & Conservatism (CONS) & 0.5329 & 0.0126 & 0.2575 & 0.8075 & 0.5183 \\
\hline & Secrecy (SECR) & 0.5446 & 0.0121 & 0.2814 & 0.8224 & 0.5300 \\
\hline
\end{tabular}

Table 2: Descriptive statistics - collected basic variables per country.

\begin{tabular}{|c|c|c|c|c|c|c|c|c|}
\hline \multirow[b]{3}{*}{ Name } & \multicolumn{4}{|c|}{ Industry Adjusted } & \multicolumn{4}{|c|}{ Industry non-Adjusted } \\
\hline & \multicolumn{2}{|c|}{ Equal } & \multicolumn{2}{|c|}{ Weight } & \multicolumn{2}{|c|}{ Equal } & \multicolumn{2}{|c|}{ Weight } \\
\hline & Mean & Std. err & Mean & Std. err & Mean & Std. err & Mean & Std. err \\
\hline \multicolumn{9}{|l|}{ Return on Assets and Accounting Regime: } \\
\hline - IASB Demanded & 0.06361 & 0.01123 & 0.09772 & 0.01378 & 0.06787 & 0.01221 & 0.09821 & 0.01465 \\
\hline - EU Demanded & 0.05048 & 0.00479 & 0.09176 & 0.00960 & 0.05150 & 0.00466 & 0.08454 & 0.00947 \\
\hline - IASB Allowed & 0.05493 & 0.00660 & 0.10928 & 0.00784 & 0.05678 & 0.00674 & 0.10827 & 0.00741 \\
\hline - IASB Disallowed & 0.06054 & 0.00720 & 0.11634 & 0.01994 & 0.06133 & 0.00709 & 0.11540 & 0.02108 \\
\hline Return on Assets - Complete & 0.05684 & 0.00417 & 0.10093 & 0.00609 & 0.05902 & 0.00443 & 0.09835 & 0.00631 \\
\hline Tobin's Q - Complete & 1.17758 & 0.06230 & 1.63202 & 0.10659 & 1.09804 & 0.06762 & 1.58833 & 0.12047 \\
\hline Earnings vs. Enterprise Value - Complete & 0.05361 & 0.01221 & 0.11377 & 0.01509 & 0.05498 & 0.01257 & 0.09658 & 0.01354 \\
\hline Sales vs. Enterprise Value - Complete & 1.83827 & 0.18680 & 1.11288 & 0.17452 & 1.88046 & 0.18858 & 1.10096 & 0.17883 \\
\hline
\end{tabular}

Table 3: Descriptive statistics for selected country-based performance measures. 
Citation: Schoeler F (2018) The Cultural Aspect of Differences in Company Performance across Countries: Gray's Accounting Values Contribute more than Hofstede's Original Cultural Dimensions. J Account Mark 7: 287. doi: 10.4172/2168-9601.1000287

economic performance (WEF), as well as the culture measures could presumably be introduced in numerous ways for which reason we only introduce a part of these in the following Table 4.

We followed the four-step procedure scheduled earlier for the two tracks, industry adjusted and industry non-adjusted respectively, see also Table 4 . In the first step the overall country wise economic business climate, WEF, is introduced. In the table we document how WEF relate to the ROA performance measure in each of the two columns A in Table 4. It seems that the basic model is better than when we in the second step introduce accounting regime dummies in each of the two columns $\mathrm{B}$ in Table 4, since the F-value as well as the adjusted $\mathrm{R} 2$ have a large decrease, and at the same time all the accounting regime coefficients seems to be not-significant at any common significance level. For this reason, it is highly questionable if accounting regimes has explanatory power. But for completeness we choose to show the next steps both with and without the accounting regime dummy variables (Table 4).

Now adding columns $\mathrm{C}$ and $\mathrm{D}$ in the third step, we deal with our second hypothesis, where we challenge the link between performance and the five Hofstede cultural indicators. It seems clear that no matter whether we focus on industry adjusted or industry non-adjusted performance, or whether we keep the accounting regime dummies in the model or not, the Hofstede cultural indicators as such add explanatory power, since the adjusted R2 increase. Concerning the Hofstede coefficients only one of them, the cultural indicator UAI (Uncertainty avoidance), is significant at acceptable levels, i.e. at $p>0.028$. However, in this setting we cannot just pick some of the cultural indicators and leave out others, since either we incorporate culture, or we do not. The positive consequence of this approach is that the multicollinearity issue which could be raised due to some (too) high variance influence factors is uninteresting, since it should be noticed that this does not violate the OLS assumptions, since the estimates are still unbiased. The standard errors are affected (upwards) making all the coefficient estimates less reliable, but a classic "repairing" solution like taking one or some of the variables out is unfortunately impossible since all variables really belong in the model. From Table 4 it seems clear, that the cultural factor as operationalized by the five Hofstede cultural indicators is important when we want to discuss, question and analyze on the reported financial performance, ROA (Table 5).

In the upper left quarter of Table 5, our country wise ROA performance measure the four variants, equal vs. market value of equity-based country averages, and industry adjusted vs. industry nonadjusted are shown. In the first section we present central characteristics from the basic model using WEF as the only performance explanatory variable (like the A columns in Table 4), i.e. the adjusted R2 and total

\begin{tabular}{|c|c|c|c|c|c|c|c|c|c|c|c|c|c|}
\hline & \multirow[b]{3}{*}{ Variable names } & \multicolumn{12}{|c|}{ Competing Models } \\
\hline & & \multicolumn{6}{|c|}{ Industry Adjusted ROA performance } & \multicolumn{6}{|c|}{ Industry non-Adjusted ROA performance } \\
\hline & & A & B & C & D & E & $\mathbf{F}$ & A & B & C & D & E & $\mathbf{F}$ \\
\hline \multirow[t]{2}{*}{ WEF } & Economic Climate in Country & -0.064 & -0.246 & -0.320 & -0.331 & -0.319 & -0.324 & -0.293 & -0.271 & -0.326 & -0.345 & -0.324 & -0.334 \\
\hline & (significance) & $(0.010)$ & $(0.024)$ & $(0.016)$ & $(0.011)$ & $(0.016)$ & $(0.012)$ & $(0.004)$ & $(0.012)$ & $(0.012)$ & $(0.007)$ & $(0.013)$ & $(0.009)$ \\
\hline \multirow[t]{2}{*}{ AR-1 } & Dummy 1 (IASB Demanded) & & 0.013 & 0.056 & & 0.024 & & & 0.046 & 0.111 & & 0.065 & \\
\hline & (significance) & & $(0.934)$ & $(0.727)$ & & $(0.881)$ & & & $(0.767)$ & $(0.482)$ & & $(0.679)$ & \\
\hline \multirow[t]{2}{*}{ AR-2 } & Dummy 2 (EU Demanded) & & -0.050 & 0.062 & & -0.140 & & & -0.034 & 0.148 & & 0.040 & \\
\hline & (significance) & & $(0.758)$ & $(0.754)$ & & $(0.941)$ & & & $(0.833)$ & $(0.447)$ & & $(0.827)$ & \\
\hline \multirow[t]{2}{*}{ AR-3 } & Dummy 3 (IASB Allowed) & & -0.033 & -0.020 & & -0.027 & & & -0.016 & 0.006 & & -0.040 & \\
\hline & (significance) & & $(0.830)$ & $(0.897)$ & & $(0.859)$ & & & $(0.917)$ & $(0.967)$ & & $(0.978)$ & \\
\hline \multirow[t]{2}{*}{ HOF-1 } & Power distance (PDI) & & & 0.013 & 0.005 & & & & & 0.025 & 0.008 & & \\
\hline & (significance) & & & $(0.922)$ & $(0.971)$ & & & & & $(0.848)$ & $(0.948)$ & & \\
\hline \multirow[t]{2}{*}{ HOF-2 } & Individualism (IDV) & & & -0.017 & 0.015 & & & & & -0.091 & -0.029 & & \\
\hline & (significance) & & & $(0.916)$ & $(0.915)$ & & & & & $(0.555)$ & $(0.831)$ & & \\
\hline \multirow[t]{2}{*}{ HOF-3 } & Masculinity (MAS) & & & 0.020 & 0.008 & & & & & 0.037 & 0.014 & & \\
\hline & (significance) & & & $(0.853)$ & $(0.939)$ & & & & & $(0.723)$ & $(0.891)$ & & \\
\hline \multirow[t]{2}{*}{ HOF-4 } & Uncertainty avoidance (UAI) & & & -0.259 & -0.238 & & & & & -0.031 & -0.270 & & \\
\hline & (significance) & & & $(0.028)$ & $(0.028)$ & & & & & $(0.008)$ & $(0.011)$ & & \\
\hline \multirow[t]{2}{*}{ HOF-5 } & Long-term orientation (LTO) & & & 0.011 & 0.008 & & & & & 0.007 & 0.011 & & \\
\hline & (significance) & & & $(0.925)$ & $(0.943)$ & & & & & $(0.949)$ & $(0.918)$ & & \\
\hline \multirow[t]{2}{*}{ GRAY-1 } & Professionalism (PROF) & & & & & 0.146 & 0.141 & & & & & 0.111 & 0.116 \\
\hline & (significance) & & & & & $(0.379)$ & $(0.368)$ & & & & & $(0.497)$ & $(0.452)$ \\
\hline \multirow[t]{2}{*}{ GRAY-2 } & Uniformity (UNIF) & & & & & -0.580 & -0.548 & & & & & -0.605 & -0.582 \\
\hline & (significance) & & & & & $(0.191)$ & $(0.196)$ & & & & & $(0.166)$ & $(0.164)$ \\
\hline \multirow[t]{2}{*}{ GRAY-3 } & Conservatism (CONS) & & & & & -0.795 & -0.794 & & & & & -0.951 & -0.905 \\
\hline & (significance) & & & & & $(0.238)$ & $(0.213)$ & & & & & $(0.152)$ & $(0.150)$ \\
\hline \multirow[t]{6}{*}{ GRAY-4 } & Secrecy (SECR) & & & & & 1.121 & 1.085 & & & & & 1.294 & 1.223 \\
\hline & (significance) & & & & & $(0.207)$ & $(0.209)$ & & & & & $(0.140)$ & $(0.152)$ \\
\hline & F-value & 6.986 & 1.769 & 1.371 & 2.041 & 1.398 & 2.276 & 8.706 & 2.232 & 1.876 & 2.663 & 1.781 & 2.864 \\
\hline & (significance F-stat) & $(0.010)$ & $(0.142)$ & $(0.214)$ & $(0.069)$ & $(0.209)$ & $(0.054)$ & $(0.004)$ & $(0.072)$ & $(0.067)$ & $(0.020)$ & $(0.092)$ & $(0.019)$ \\
\hline & Adjusted R-squared & 0.060 & 0.032 & 0.034 & 0.062 & 0.033 & 0.064 & 0.076 & 0.050 & 0.077 & 0.096 & 0.062 & 0.090 \\
\hline & $\mathrm{VIF}<$ (highest number stated) & 1.000 & 2.496 & 3.830 & 1.864 & 75.755 & 73.931 & 1.000 & 2.496 & 3.830 & 1.864 & 75.755 & 73.931 \\
\hline \multicolumn{4}{|c|}{$\mathrm{P}$-values (reported in parentheses) are two-tailed. } & & & & & & & & & & \\
\hline
\end{tabular}

Table 4: Results from multiple regression analyses for Return on Assets. 
Citation: Schoeler F (2018) The Cultural Aspect of Differences in Company Performance across Countries: Gray's Accounting Values Contribute more than Hofstede's Original Cultural Dimensions. J Account Mark 7: 287. doi: 10.4172/2168-9601.1000287

Page 7 of 8

\begin{tabular}{|c|c|c|c|c|c|c|c|c|c|}
\hline \multirow[t]{2}{*}{ Return On Assets } & \multicolumn{2}{|c|}{ Industry Adjusted } & \multicolumn{2}{|c|}{ Industry non-Adjusted } & \multirow[t]{2}{*}{ Tobin's Q } & \multicolumn{2}{|c|}{ Industry Adjusted } & \multicolumn{2}{|c|}{ Industry non-Adjusted } \\
\hline & Equal & Weight & Equal & Weight & & Equal & Weight & Equal & Weight \\
\hline $\begin{array}{l}\text { Independent variables: WEF } \\
\rightarrow>\mathrm{K}=\end{array}$ & 1 & 1 & 1 & 1 & $\begin{array}{l}\text { Independent variables: } \\
\text { WEF } \rightarrow \mathrm{K}=\end{array}$ & 1 & 1 & 1 & 1 \\
\hline Adj. $R^{2}$ & 0.060 & 0.052 & 0.076 & 0.042 & Adj. $R^{2}$ & -0.008 & -0.005 & 0.007 & -0.010 \\
\hline SSE & 0.160 & 0.341 & 0.176 & 0.371 & SSE & 38.022 & 111.009 & 44.143 & 142.519 \\
\hline $\begin{array}{c}\text { Independent variables: } \\
\text { WEF; HOF } \rightarrow \mathrm{K}=\end{array}$ & 6 & 6 & 6 & 6 & $\begin{array}{l}\text { Independent variables: } \\
\text { WEF; HOF } \rightarrow \mathrm{K}=\end{array}$ & 6 & 6 & 6 & 6 \\
\hline Adj. $R^{2}$ & 0.062 & 0.097 & 0.096 & 0.167 & Adj. $R^{2}$ & 0.025 & 0.112 & 0.063 & 0.134 \\
\hline SSE & 0.136 & 0.280 & 0.148 & 0.277 & SSE & 31.630 & 84.315 & 35.823 & 105.076 \\
\hline $\mathrm{AlC}_{\mathrm{c}}$ & -252.523 & -222.729 & -249.035 & -223.174 & $\mathrm{AlC}_{\mathrm{c}}$ & -27.700 & 12.752 & -22.564 & 21.834 \\
\hline \multirow{2}{*}{$\begin{array}{l}\text { F-test (Restricted vs. } \\
\text { Unrestricted) }\end{array}$} & 3.041 & 3.834 & 3.330 & 5.954 & \multirow{2}{*}{$\begin{array}{l}\text { F-test (Restricted vs. } \\
\text { Unrestricted) }\end{array}$} & 3.556 & 5.572 & 4.088 & 6.272 \\
\hline & $(0.0140)$ & $(0.0034)$ & $(0.0084)$ & $(0.0001)$ & & $(0.0056)$ & $(0.0002)$ & $(0.0022)$ & $(0.0001)$ \\
\hline $\begin{array}{l}\text { Independent variables: } \\
\text { WEF; GRAY } \rightarrow \text { K= }\end{array}$ & 5 & 5 & 5 & 5 & $\begin{array}{l}\text { Independent variables: } \\
\text { WEF; GRAY }>\text { K= }\end{array}$ & 5 & 5 & 5 & 5 \\
\hline Adj. $R^{2}$ & 0.064 & 0.099 & 0.090 & 0.154 & Adj. $R^{2}$ & 0.002 & 0.094 & 0.037 & 0.103 \\
\hline SSE & 0.138 & 0.282 & 0.151 & 0.285 & SSE & 32.749 & 87.070 & 37.233 & 110.082 \\
\hline $\mathrm{AlC}_{\mathrm{c}}$ & -254.308 & -224.823 & -250.594 & -224.386 & $\mathrm{AlC}_{\mathrm{c}}$ & -28.653 & 11.691 & -23.358 & 21.367 \\
\hline \multirow{2}{*}{$\begin{array}{l}\text { F-test (Restricted vs. } \\
\text { Unrestricted) }\end{array}$} & 3.467 & 4.655 & 3.684 & 6.691 & \multirow{2}{*}{$\begin{array}{l}\text { F-test (Restricted vs. } \\
\text { Unrestricted) }\end{array}$} & 3.582 & 6.117 & 4.129 & 6.556 \\
\hline & $(0.0111)$ & $(0.0019)$ & $(0.0080)$ & $(0.0001)$ & & $(0.0093)$ & $(0.0002)$ & $(0.0041)$ & $(0.0001)$ \\
\hline $\begin{array}{l}\text { Akaike Criterion Ratios: } \\
\text { AIC }{ }_{\mathrm{c}} \text { GRAY vs. HOF }\end{array}$ & 2.439 & 2.848 & 3.155 & 1.834 & $\begin{array}{l}\text { Akaike Criterion Ratios: } \\
\text { AIC }_{c} \text { GRAY vs. HOF }\end{array}$ & 1.610 & 1.700 & 1.488 & 1.263 \\
\hline \multirow{2}{*}{$\begin{array}{l}\text { Earnings vs. Enterprise } \\
\text { Value }\end{array}$} & \multicolumn{2}{|c|}{ Industry Adjusted } & \multicolumn{2}{|c|}{ Industry non-Adjusted } & \multirow{2}{*}{$\begin{array}{l}\text { Sales vs. Enterprise } \\
\text { Value }\end{array}$} & \multicolumn{2}{|c|}{ Industry Adjusted } & \multicolumn{2}{|c|}{ Industry non-Adjusted } \\
\hline & Equal & Weight & Equal & Weight & & Equal & Weight & Equal & Weight \\
\hline $\begin{array}{c}\text { Independent variables: WEF } \\
\rightarrow>\mathrm{K}=\end{array}$ & 1 & 1 & 1 & 1 & $\begin{array}{l}\text { Independent variables: } \\
\text { WEF } \rightarrow \mathrm{K}=\end{array}$ & 1 & 1 & 1 & 1 \\
\hline Adj. $R^{2}$ & 0.004 & 0.060 & 0.005 & 0.039 & Adj. $R^{2}$ & 0.024 & 0.009 & 0.033 & 0.021 \\
\hline SSE & 1.444 & 2.080 & 1.528 & 1.713 & SSE & 331.086 & 293.193 & 334.156 & 304.237 \\
\hline $\begin{array}{c}\text { Independent variables: } \\
\text { WEF; HOF }>\mathrm{K}=\end{array}$ & 6 & 6 & 6 & 6 & $\begin{array}{l}\text { Independent variables: } \\
\text { WEF; HOF } \rightarrow \mathrm{K}=\end{array}$ & 6 & 6 & 6 & 6 \\
\hline Adj. $R^{2}$ & -0.035 & 0.012 & -0.025 & -0.001 & Adj. $R^{2}$ & 0.031 & -0.022 & 0.036 & -0.015 \\
\hline SSE & 1.291 & 1.882 & 1.354 & 1.536 & SSE & 282.603 & 260.333 & 286.478 & 271.385 \\
\hline $\mathrm{AIC}_{\mathrm{c}}$ & -159.671 & -144.121 & -157.706 & -152.502 & $\mathrm{AlC}_{\mathrm{c}}$ & 62.653 & 59.266 & 63.214 & 60.981 \\
\hline \multirow{2}{*}{$\begin{array}{l}\text { F-test (Restricted vs. } \\
\text { Unrestricted) }\end{array}$} & 2.090 & 1.853 & 2.260 & 2.025 & \multirow{2}{*}{$\begin{array}{l}\text { F-test (Restricted vs. } \\
\text { Unrestricted) }\end{array}$} & 3.019 & 2.222 & 2.929 & 2.131 \\
\hline & $(0.0741)$ & $(0.1109)$ & $(0.0553)$ & $(0.0829)$ & & $(0.0146)$ & $(0.0591)$ & $(0.0171)$ & $(0.0691)$ \\
\hline $\begin{array}{l}\text { Independent variables: } \\
\text { WEF; GRAY } \rightarrow \text { K= }\end{array}$ & 5 & 5 & 5 & 5 & $\begin{array}{l}\text { Independent variables: } \\
\text { WEF; GRAY } \rightarrow \text { K= }\end{array}$ & 5 & 5 & 5 & 5 \\
\hline Adj. $R^{2}$ & -0.024 & 0.020 & -0.016 & 0.010 & Adj. $R^{2}$ & 0.038 & -0.011 & 0.044 & -0.004 \\
\hline SSE & 1.292 & 1.886 & 1.357 & 1.536 & SSE & 283.717 & 260.347 & 287.522 & 271.398 \\
\hline $\mathrm{AIC}_{\mathrm{c}}$ & -162.026 & -146.420 & -160.001 & -154.889 & $\mathrm{AlC}_{\mathrm{c}}$ & 60.428 & 56.881 & 60.977 & 58.596 \\
\hline \multirow{2}{*}{$\begin{array}{l}\text { F-test (Restricted vs. } \\
\text { Unrestricted) }\end{array}$} & 2.623 & 2.290 & 2.802 & 2.560 & \multirow{2}{*}{$\begin{array}{l}\text { F-test (Restricted vs. } \\
\text { Unrestricted) }\end{array}$} & 3.715 & 2.817 & 3.609 & 2.692 \\
\hline & $(0.0400)$ & $(0.0659)$ & $(0.0305)$ & $(0.0440)$ & & $(0.0076)$ & $(0.0303)$ & $(0.0090)$ & $(0.0360)$ \\
\hline $\begin{array}{l}\text { Akaike Criterion Ratios: } \\
\text { AIC } \text { GRAY vs. HOF }^{\text {G }}\end{array}$ & 3.253 & 3.159 & 3.155 & 3.304 & $\begin{array}{l}\text { Akaike Criterion Ratios: } \\
\text { AIC }_{c} \text { GRAY vs. HOF }\end{array}$ & 3.045 & 3.296 & 3.057 & 3.289 \\
\hline
\end{tabular}

Calculation of $\mathrm{AIC}_{\mathrm{c}}$ following K. P. Burnham \& D. R. Anderson (2002): Model selection and multimodel inference. A practical information-theoretic approach , Springer

Table 5: Results from various model selection procedures.

sums of squared errors, SSE. The second section shows characteristics from same but with the five Hofstede cultural indicators added. The F-test values (Restricted vs. Unrestricted model) are the results of the statistical pairwise comparison of these models to the similar without the Hofstede indicators. The results show, that for generally reasonable choices of significance levels, i.e. at $\mathrm{p}>0.0140$, the models including the Hofstede cultural indicators are better than without. Likewise, for the third section we present results from same but including characteristics adding the four Gray accounting values instead of the Hofstede cultural indicators added previously.

The F-test values (Restricted vs. Unrestricted model) in this section are the results of the statistical pairwise comparison of these models to the similar without the Gray accounting values, i.e. the models in the first section. The results show that for reasonable choices of significance levels, i.e. at $\mathrm{p}>0.0111$, the models including the Gray accounting values are better than without. In the second and in the third section we also present Akaike criterion calculations, AICC, and in the fourth section we present the ratio between these pairwise Akaike calculations based on Hofstede and Gray variables, which can be used as a selection criterion. In all cases the models including Gray's accounting values should be preferred from the models including Hofstede's cultural indicators since the Akaike Criterion ratio is above one. According to Burnham and Anderson [31], the model including the Gray variables is convincingly better than the model including the Hofstede variables when the Akaike Criterion ratio statistic is larger than 2.000, which is the case here for three out of four variants of the calculated countrywise performance measure ROA. 
Citation: Schoeler F (2018) The Cultural Aspect of Differences in Company Performance across Countries: Gray's Accounting Values Contribute more than Hofstede's Original Cultural Dimensions. J Account Mark 7: 287. doi: 10.4172/2168-9601.1000287

The results for same structural models for the other three performance measures are also presented in Table 5. Overall the same pattern is shown, but it is not completely clear as for ROA, and the relation between the explanatory variable and the explained variable as such is also less clear than for the ROA. For the multiples performance measures, Gray is convincingly better than Hofstede, while Gray is only better (not convincingly) for Tobin's Q. And the introduction of the Hofstede cultural indicators is not statistically clear for the two multiples performance measures as for Tobin's Q and for ROA. However, in general there should be no doubt that the use of Gray accounting values leaves better explanatory models for the performance than Hofstede cultural indicators, and as such should be preferred.

\section{Conclusion}

Summarizing, we find support for our expectations as expressed in hypotheses $\mathrm{H} 2$ and $\mathrm{H} 3$, while the expectations in hypothesis $\mathrm{H} 1$ were not justified by our results. Prescribed accounting regimes expressed relatively in relation to IFRS seems to have no explanatory power as to differences in performance between companies grouped in countries, which might simply reflect that the IFRS leaves many choices in detailed accounting practice to the user for which reason our countrybased averages were not able to show differences.

Concerning the cultural effect, the Hofstede cultural indicators help explaining the differences between country-levels of company performance across countries confirming that culture is an issue leading to difference in performance between countries. The Gray accounting values as another way of operationalizing cultural effects help explaining differencing in company performance on a grouped country-level, which could be taken into consideration when comparing companies' performance across countries.

Further, concerning the cultural effect, the Gray accounting values as operationalized and implemented here seem to better capture the differences in average performance in different countries than the Hofstede cultural indicators do.

\section{References}

1. Ding $Y$, Jeanjean T, Stolowy $H$ (2005) Why do national GAAP differ from IAS? The role of culture. Inter J Accounting 40: 325-350.

2. Zarzeski MT (1996) Spontaneous harmonization effects of culture and market forces on accounting isclosure practices. Accounting Horizons 10: 18-37.

3. Nobes C (1998) Towards a general model of the reasons for internationa differences in financial reporting. Abacus 34: 162-187.

4. Hofstede G (1980) Culture's consequences: international differences in workrelated values. Integral edition. Beverly Hills, CA: Sage.

5. Hofstede G (2001) Culture's consequences: comparing values, behaviors institutions, and organizations across nations. ( $\left.2^{\text {nd }} E d n\right)$ London: Sage Publications.

6. Gray SJ (1988) Towards a theory of cultural influence on the development of accounting systems internationally. Abacus 24: 1-15.

7. Radebaugh LH, Gray SJ, Black EL (2006) International accounting and multinational enterprises (6th Edn) Wiley.

8. DeFranco G, Kothari SP, Verdi S (2011) The benefits of financial statement comparability. J Accounting Res 49: 895-931.
9. International Accounting Standards Board (2018). Conceptual Framework for Financial Reporting, IASB.

10. Sunder S (2011) IFRS monopoly: The Pied Piper of financial reporting Accounting and Business Research 41: 291-306.

11. Violet WJ (1983) The development of international accounting standards: An anthropological perspective. The Inter J Accounting Edu and Res 18: 1-12.

12. Perera $H$ (1989) Towards a framework to analyze the impact of culture on accounting. Inter J Accounting 24: 42-56.

13. Noravesh I, Dilami ZD, Bazaz MS (2007). The impact of culture on accounting: does Gray's model apply to Iran? Review of Accounting and Finance 6: 254272.

14. Salter SB, Lewis PA (2011) Shades of Gray: An empirical examination of Gray's model of culture and income measurement practices using 20-F data. Advances in Accounting, incorporating Advances in International Accounting 27: $132-142$

15. Tsakumis GT (2007) The influence of culture on accountants' application of financial rules. Abacus 43: 27-48.

16. Doupnik TS, Riccio EL (2006) The influence of conservatism and secrecy on the interpretation of verbal probability expressions in the Anglo and Latin cultural areas. Inter J Accounting 41: 237-261.

17. Jaggi B, Lowy PY (2000) Impact of culture, market forces, and legal system on financial disclosures. Inter J Accounting 35: 495-519.

18. Braun GP, Rodriguez RP (2008) Earnings management and accounting values: A test of Gray (1988). J International Accounting Research 7: 1-23.

19. Leuz G, Nanda D, Wysocki $P$ (2003) Investor protection and earnings management: An international comparison. J Financial Economics 69: 505527

20. Chanchani S, Willet R (2004) An empirical assessment of Gray's accounting value constructs. Inter J Accounting 39: 125-154.

21. Chanchani S, MacGregor A (1999) A synthesis of cultural studies in accounting J Accounting Literature 18: 1-30.

22. Doupnik TS, Tsakumis GT (2004) A critical review of tests of Gray's theory of cultural relevance and suggestions for future research. J Accounting Literature 23: 1-48.

23. McSweeney B (2002) Hofstede's model of national cultural differences and their consequences: A triumph of faith $-a$ failure of analysis. Human Relations 55: 89-118.

24. Baskerville RF (2003) Hofstede never studied culture. Accounting Organizations and Society 28: 1-14.

25. Schwartz SH (1994) Beyond individualism/collectivism: New cultural dimensions of values. In Kim U, Triandis HC, Kagitchibasi C, Choi SC, Yoon $\mathrm{G}$ Individualism and Collectivism: Theory, method and applications, Newbury Park, London: Sage.

26. Shenkar O (2001) Cultural distance revisited: Towards a more rigorous conceptualization and measurement of cultural differences. J International Business Studies 32: 519-532.

27. Hope OK (2003) Firm-level disclosures and the relative roles of culture and legal origin. J Inter Financial Management and Accounting 14: 218-248.

28. Joannides V, Wickramasinghe D, Berland N (2012) Critiques on GrayHofstede's model: What impact on cross-cultural accounting research?

29. Fama EF, French KR (1997) Industry costs of equity. J Financial Economics 43: 153-193.

30. Price Waterhouse Coopers (2015) IFRS adoption by country 64: 59-81.

31. Burnham KP, Anderson DR (2002) Model selection and multimodal inference. A practical information-theoretic approach, Springer. 